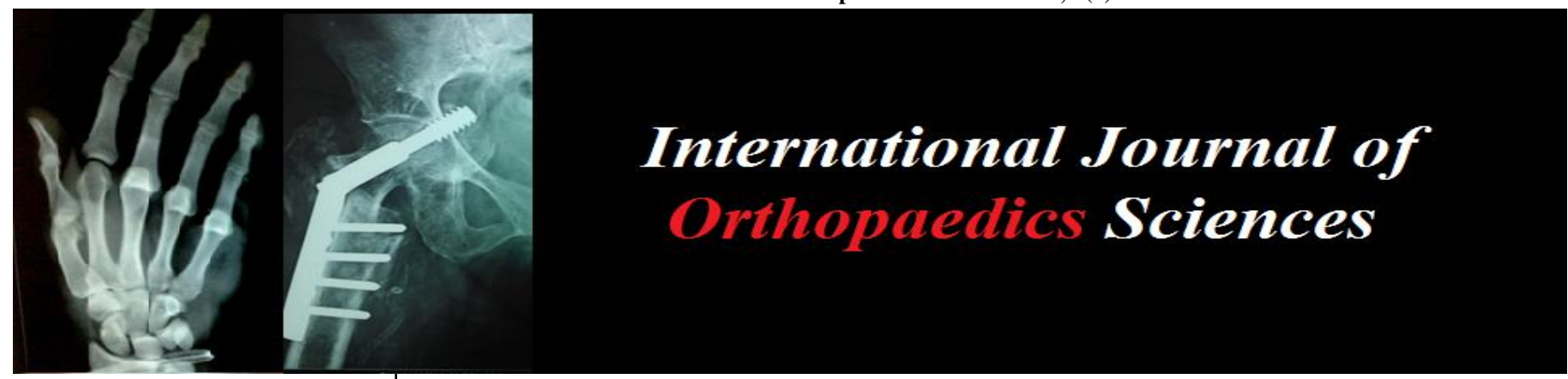

E-ISSN: 2395-1958

P-ISSN: 2706-6630

IJOS 2019; 5(4): 666-672

(C) 2019 IJOS

www.orthopaper.com

Received: 09-08-2019

Accepted: 13-09-2019

Thundathil Gangadharan Sreejith Associate Professor, Department of Orthopedics, K.M.C.T. Medical College, Calicut, Kerala, India

\section{Adold George}

Assistant Professor, Department of Orthopedics, K.M.C.T.

Medical College, Calicut, Kerala India
Corresponding Author:

Thundathil Gangadharan Sreejith Associate Professor, Department of Orthopedics, K.M.C.T. Medical College, Calicut, Kerala, India

\section{Is direct reduction and rigid fixation osteosynthesis better than ligamentotaxis for comminuted intra articular lower end radius fractures?}

\author{
Thundathil Gangadharan Sreejith and Adold George
}

DOI: https://doi.org/10.22271/ortho.2019.v5.i41.1751

\section{Abstract}

Introduction: The distal radius has a complex kinematics for the radiocarpal and the radioulnar joints. Perfect restoration of the radial length, volar angulation and radial inclination are mandatory for complete restoration of the wrist function. Ligamentotaxis, and Open Reduction with Internal Fixation (ORIF) are the most commonly practiced two methods, to achieve the above goals in the current era of Orthopedic Practice. In this study, the functional and radiological outcomes of both Direct Reduction and Rigid fixation (ORIF with Volar Plating) and Ligamentotaxis were analyzed, to find out the best option among the two.

Materials and Methods: This Prospective study was conducted in Department of Orthopedics KMCT medical college, a tertiary level health delivery institution in South India, from April 2017 to September 2018, of age group, 20 to 70 years, with Isolated closed distal end radius fracture not older than two weeks and classified as AO TYPE C -Distal end radius fracture. Those with Pregnancy, Polytrauma, other injuries in ipsilateral limb and presence of space occupying lesion at wrist were excluded from the study. Twenty patients were selected for each group, and the results were statistically analyzed using Statistical Package for Social Sciences (SPSS) 20.0 software.

Results and Conclusions: In our study, on the analysis of the functional and radiological outcomes, we found there are significant advantages for volar locking plate over Ligamentotaxis, as early mobilization of the wrist and less intra/post-operative complications. Hence, it is definitely a better choice for managing Comminuted Intra Articular Distal End Radius Fractures.

Keywords: Hip fracture; bone turnover markers; CTX; PINP; vitamin D

\section{Introduction}

Distal end radius fractures are one of the most common injuries encountered in orthopedic practice. They make up $8 \%-15 \%$ of all bony injuries in adults ${ }^{[1]}$. These injuries have been noted to develop malunion in many occasions which provide a less satisfactory functional and cosmetic outcome. As the distal radius forms the cornerstone for kinematics of the radiocarpal and the radioulnar joints, near normal restoration of the radial length, volar angulation and radial inclination are important pre-requisites for obtaining good wrist function ${ }^{2}$. Based on decades of extensive research, surgeons have developed multiple approaches for the treatment of distal radius fractures, including both conservative and non-conservative options. These options include closed reduction and casting, closed reduction and percutaneous pinning, external fixation, and open reduction with internal fixation (ORIF) ${ }^{[3]}$. In this study, we compared the functional and radiological outcomes between direct (open) reduction and rigid internal fixation osteosynthesis with volar plating and Ligamentotaxis plus $\mathrm{K}$ wire fixation.

Ligamentotaxis is a method of indirect reduction and osteosynthesis, which has the advantages ${ }^{[4]}$ like This maintaining the length and alignment of fracture fragments ${ }^{[5]}$. At the same time osteosynthesis by volar locking plate is a direct method of fracture reduction by which fracture is exposed, reduced and fixed with locking plate $\&$ screws on volar aspect of radius ${ }^{[6]}$.

\section{Relevant anatomy}

Distal end of radius act as an articular surface where carpal bones rest and from there radially 
oriented supporting ligaments arises. Wrist joint as unit articulates and rotates around ulnar head via the sigmoid notch of ulna.

Distal end of radius consists of three concave articular surfaces- the scaphoid fossa, the lunate fossa and the sigmoid notch for articulation with scaphoid, lunate and ulnar head respectively ${ }^{[7]}$.

\section{Ligaments}

Carpal bones and ulnar head attached to distal end of radius through number of ligaments which helps in stability, transferring load and kinematics of wrist joint ${ }^{[8]}$.

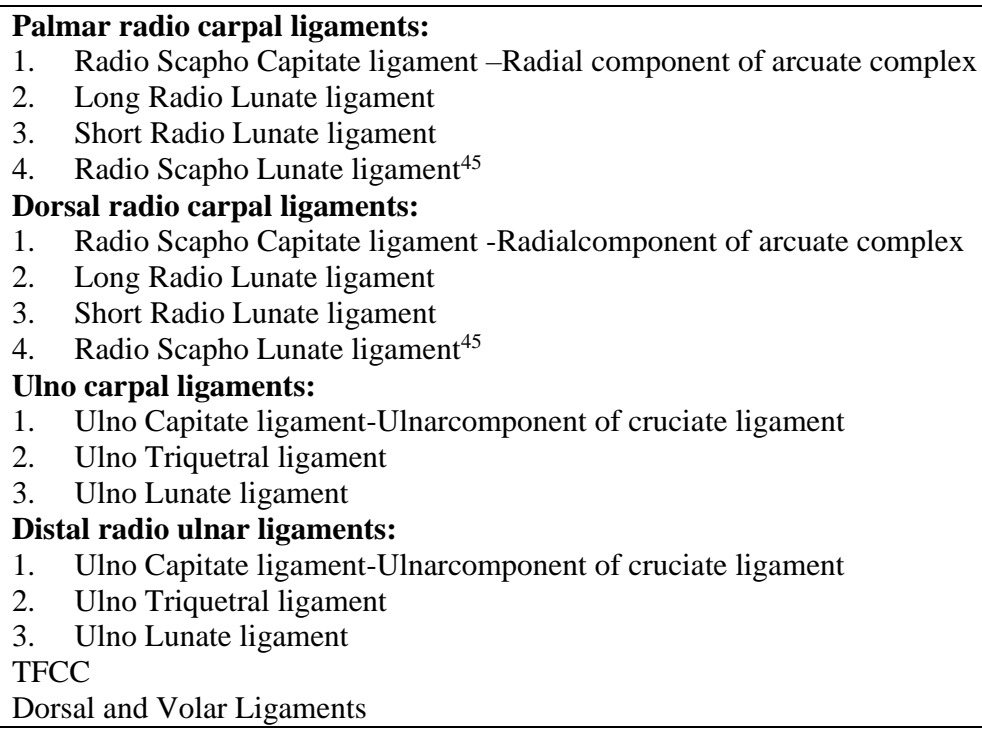

1. Radio Scapho Capitate ligament-Radialcomponent of arcuate complex

2. Long Radio Lunate ligament

3. Short Radio Lunate ligament

4. Radio Scapho Lunate ligament ${ }^{45}$

Ulno carpal ligaments:

1. Ulno Capitate ligament-Ulnarcomponent of cruciate ligament

2. Ulno Triquetral ligament

3. Ulno Lunate ligament

Distal radio ulnar ligaments:

1. Ulno Capitate ligament-Ulnarcomponent of cruciate ligament

2. Ulno Triquetral ligament

3. Ulno Lunate ligament

TFCC

Dorsal and Volar Ligaments

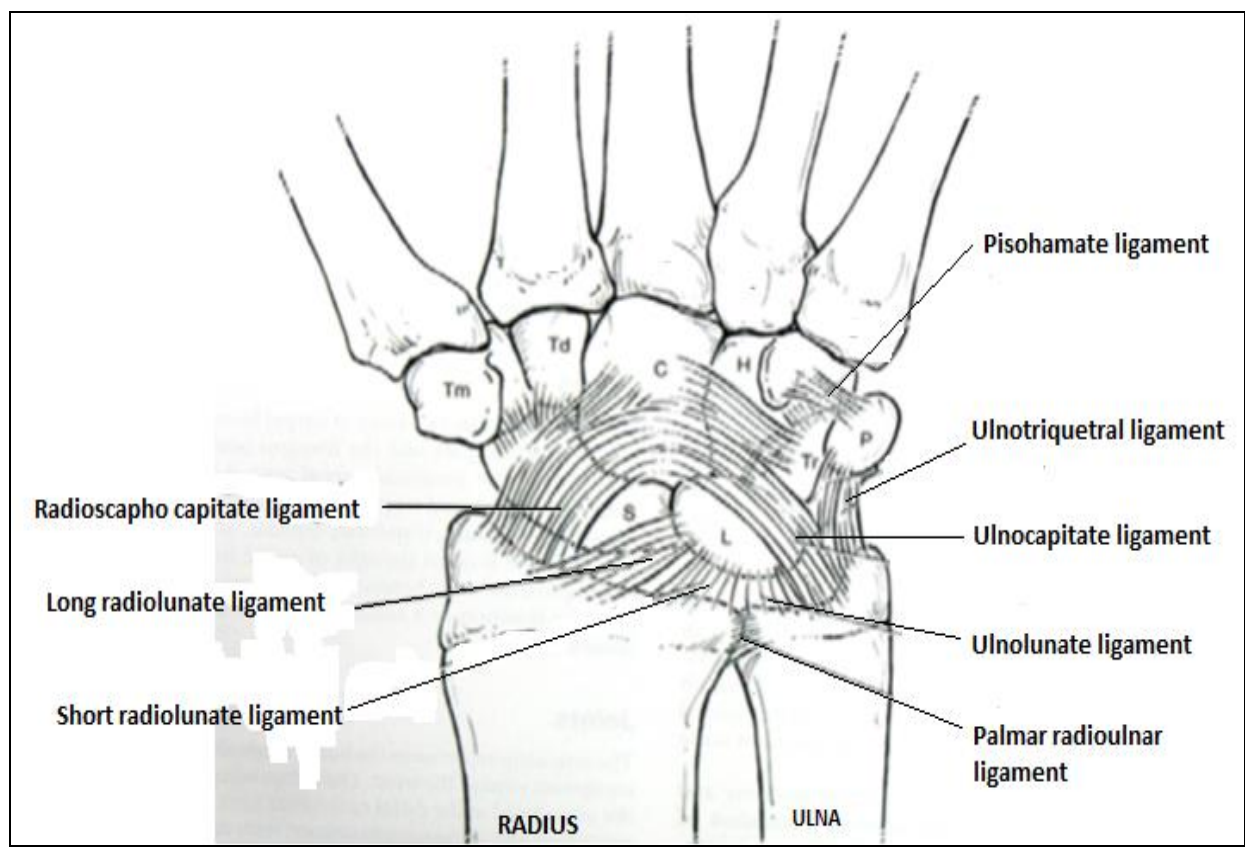

\section{Volar Ligaments}

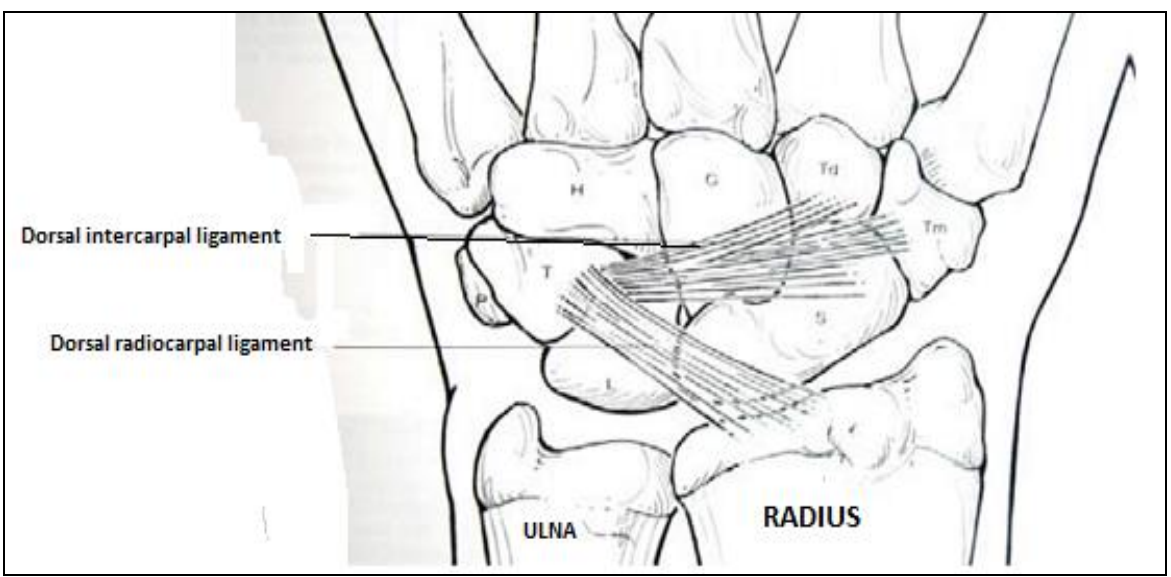

Dorsal Ligaments 


\section{Kinematics of the wrist joint}

The Capitate acts as the center of rotation of wrist joint. Wrist flexion and extension occur equally through radio carpal and midcarpal joints. $60 \%$ of radial and ulnar deviations occur through midcarpal joint and $40 \%$ through radio carpal joint ${ }^{9}$.

\section{Normal range of movements}

Flexion 0 to $70-90^{\circ}$

Extension 0 to $70-90^{\circ}$

Radial deviation 0 to $15-25^{\circ}$

Ulnar deviation 0 to $25-35^{\circ}$

Supination 0 to $70-90^{\circ}$

Pronation 0 to $70-90^{\circ}$

Normally, $82 \%$ of the axial load at the wrist is from Radius and $18 \%$ by ulna.

\section{Radiological anatomy}

Radial length or height

Normal radial length is $11-12 \mathrm{~mm}$.

\section{Radial angulation or inclination}

Normal is $22-23^{\circ}$.

\section{Ulnar variance}

Normal is $0.9-1 \mathrm{~mm}$.

\section{Palmar tilt}

Normal is $11-12^{\circ}$

In a suspected case of fracture of distal radius, standard antero-posterior and lateral views are taken ${ }^{10}$.

\section{Mechanism of injury}

Most common mechanism of distal end radius fracture is fall on outstretched hand.

Fracture pattern can vary according to following variables

1. Velocity

2. Position of hand and wrist at impact

3. Degree of rotation of forearm

4. The individual's bone quality and density

Usually In a fall the forearm is pronated and the hand and wrist extended, the body weight of the patient is transmitted through the axis of radius resulting in bending forces at the level of metaphyseal region of radius bone. Volar cortex breaks under tensile stress and the dorsal cortex breaks from compressive forces at impaction. Impaction and collapse of the cancellous bone of the metaphysis also occur due to penetration of the harder and stiffer cortical bone at the proximal diaphyseal section. With dorsally displaced fractures, the distal fragment supinates with respect to the radial diaphysis.

Ulnar styloid fractures have been identified in approximately $50-60 \%$ of distal radius fractures. The Triangular Fibro Cartilage can be injured with or without an associated fracture of ulnar styloid ${ }^{[11]}$.

\section{Management}

Distal end of radius fractures can be managed by both conservative and surgical methods. Among the conservative methods, Ligamentotaxis is the most commonly followed procedure, where as in ORIF, Volar locking plate osteosynthesis is the most common technique ${ }^{[12]}$.

\section{Materials and Methods}

We compared the functional and radiological outcomes following volar locking plate and ligamentotaxis plus $\mathrm{k}$ wire fixation in intra-articular fractures of distal end radius fracture. Our research also focused on intraoperative and post operative complications. Functional outcomes were studied using Gartland and Werley Score (demerit system) ${ }^{[13]}$ and the radiological outcomes using Sarmiento Radiological Score (modified from Lidström and Frykman) ${ }^{[14]}$.

\section{Surgical procedures}

With proper preoperative evaluations, and work up, under, regional anesthesia (brachial block with aid of Ultrasound guidance with nerve stimulator, under all aseptic precautions, both Ligamentotaxis and ORIF with Volar Locking plates were carried out $\mathrm{C}$ arm control, in both study groups, from April 2017 to September 2018 at our Institution.

Post operatively, active finger movements, elevation of the limb, parenteral followed by oral antibiotics, dressings, regular follow ups and radiological examinations were done in both the study groups, as per the standard protocols.

\section{Observations and Results}

Mean age of the study participants: $47.70 \pm 17.01$

\section{Distribution based on gender of the total population}

Mean age of the population was 47.7 with 16 male (40\%) and 24 female (60\%).Standard deviations were 15.05 for male and 18.28 for females. Out of the 16 males in study group $11(55 \%)$ underwent ligamentotaxis and $5(25 \%)$ underwent volar locking plate. Out of 14 females $9(45 \%)$ underwent ligamentotaxis $+\mathrm{k}$ wire and $15(75 \%)$ underwent volar locking plate fixation.

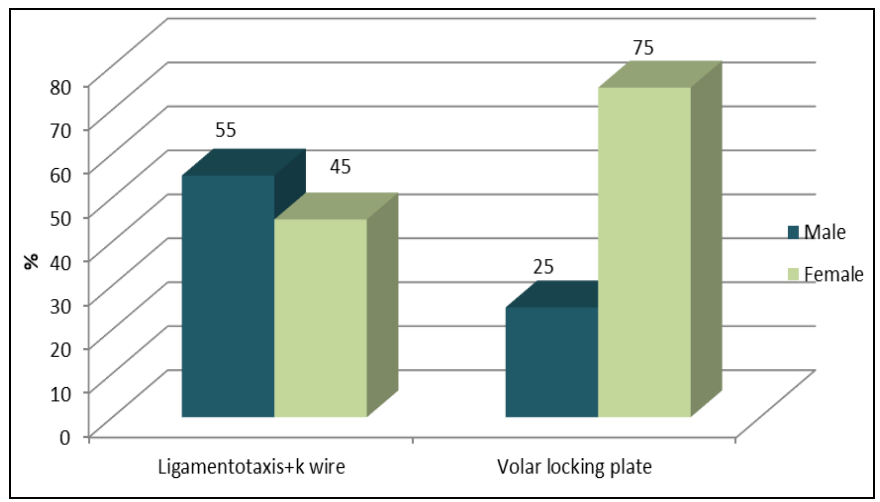

Fig 1: Distribution based on gender of total population

\section{Distribution based on age group}

Among the study group 35\% was from age group 51-60, $22.5 \%$ between 20 and 30 as well as greater than 60 year old, $17.5 \%$ patients were of age group 31-40 and least no. of patients were from $41-50(2.5 \%)$.

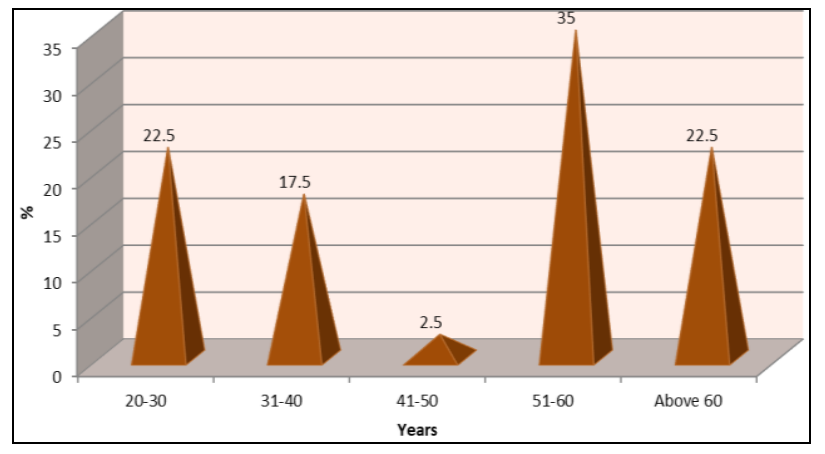

Fig 2: Distribution based on age group 
Table 1: Traetment Options

\begin{tabular}{|c|c|c|}
\hline Treatment & Mean Age & SD \\
\hline Ligamentotaxis+k wire & 51.0 & 18.11 \\
\hline Volar locking plate & 44.4 & 15.58 \\
\hline
\end{tabular}

Mean age of study group underwent ligamentotaxis $+\mathrm{k}$ wire was $51 \%$ and volar locking plate was $44 \%$

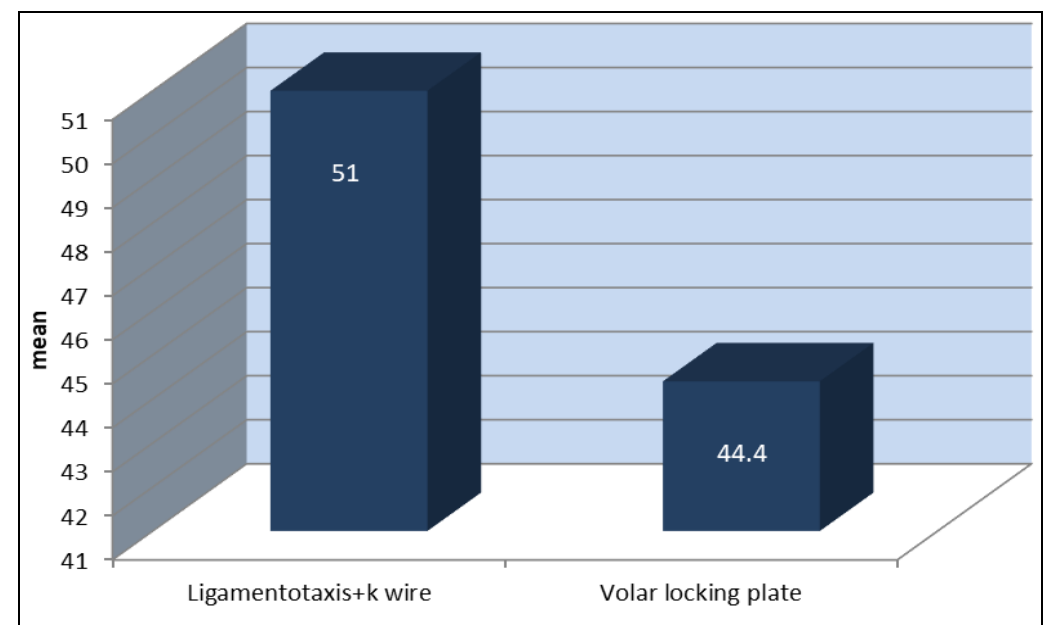

Fig 3: Distribution based on age group

Table on distribution based on mode of injury

Mode of injury was either RTA or self fall, with both categories had 50\% (20 each) in our study group

Table 2: Distribution based on mode of injury

\begin{tabular}{|c|c|c|}
\hline Injury & $\mathbf{n}$ & $\boldsymbol{\%}$ \\
\hline Road traffic accident & 20 & 50 \\
\hline Self fall & 20 & 50 \\
\hline
\end{tabular}

Table on Distribution of treatment given

Study group was divided equally with $50 \%$ cases undergoing ligamentotaxis while remaining 50\% underwent volar locking plate.

Table 3: Distribution based on treatment given

\begin{tabular}{|c|c|c|}
\hline Treatment & N & \% \\
\hline Ligamentotaxis+k wire & 20 & 50 \\
\hline Volar locking plate & 20 & 50 \\
\hline
\end{tabular}

Study group was divided equally with $50 \%$ cases undergoing ligamentotaxis while remaining $50 \%$ underwent volar locking plate.

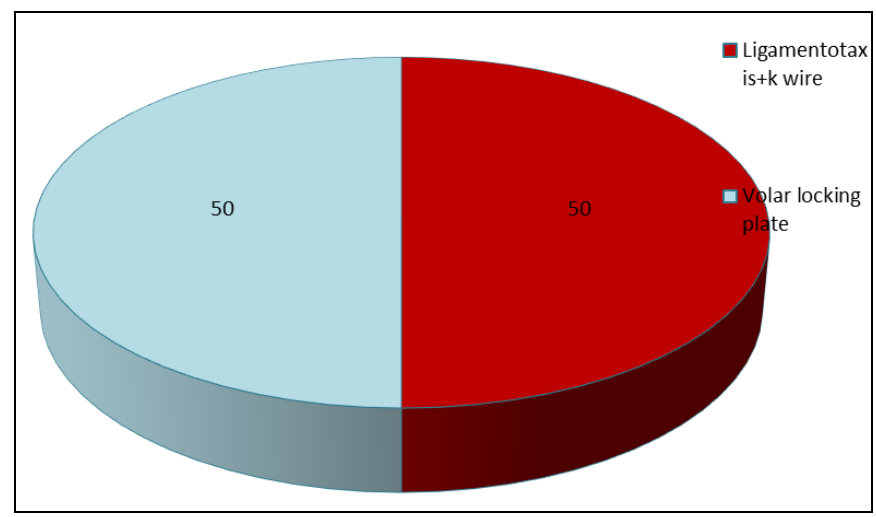

Fig 4: Distribution based on treatment given

\section{Intra operative and post operative complications}

In total; study group underwent Ligamentotaxis had more intra operative complications than those who underwent Volar locking plate.

In detail those who underwent Ligamentotaxis: Neurovascular injury $5.0 \%$, Broken implant $10.0 \%$ and Metacarpal fracture $5.0 \%$

But for those who underwent Volar locking plate have Neurovascular injury $10.0 \%$ and no Iatrogenic fracture or Broken implants.

Table 4: Intra operative complications

\begin{tabular}{|c|c|c|c|}
\hline Complications & Neurovascular injury N (\%) & Broken implant N (\%) & Metacarpal fracture n (\%) \\
\hline Ligamentotaxis + k wire & $1(5.0)$ & $2(10.0)$ & $2(5.0)$ \\
\hline Volar locking plate & $2(10.0)$ & 0 & 0 \\
\hline
\end{tabular}


Table 5: Post operative complications

\begin{tabular}{|c|c|c|c|c|c|c|}
\hline Treatment & $\begin{array}{c}\text { Complex regional pain } \\
\text { syndrome (CRPS) }\end{array}$ & $\begin{array}{c}\text { Joint } \\
\text { stiffness }\end{array}$ & Mal union & Neuropraxia & $\begin{array}{c}\text { Pin tract } \\
\text { infection }\end{array}$ & $\begin{array}{c}\text { Wound } \\
\text { infection }\end{array}$ \\
\hline Ligamentotaxis + k wire & $1(5.0)$ & $2(10.0)$ & $4(20.0)$ & $1(5.0)$ & $4(20.0)$ & 0 \\
\hline Volar locking plate & $1(5.0)$ & $1(5.0)$ & 0 & $2(10.0)$ & 0 & $2(10.0)$ \\
\hline
\end{tabular}

Comparison between gartland and werley score in both the treatment groups at various intervals

Ligamentotaxis and volar locking plate were compared with Gartland and Werley score at 3 weeks, 6 weeks, 3 months, 6 months.

With ligamentotaxis, Mean Values were $16.85 \pm 2.53,12.25 \pm$ $2.99,8.65 \pm 2.97$ and $6.30 \pm 3.11$ respectively and with Volar locking, Mean Values were $13.25 \pm 3.19,9.35 \pm 2.20,6.25 \pm$ 1.80 and $4.10 \pm 2.59$ respectively.

$\mathrm{P}$ value was calculated and found to be highly significant at 3 weeks $(<0.001)$ and significant at 6 weeks, 3 months and 6 months.

In our study in terms of post-operative functional outcome by using Gartland and Werley score we found that Volar locking plate is superior to Ligamentotaxis in Distal end radius fractures.
Table 6: Comparison between Gartland \& Werley score in both the treatment groups at various intervals

\begin{tabular}{|c|c|c|c|c|c|}
\hline \multirow{2}{*}{ Intervals } & \multicolumn{2}{|c|}{$\begin{array}{c}\text { Ligamentotaxis + k } \\
\text { wire }\end{array}$} & \multicolumn{2}{c|}{$\begin{array}{c}\text { Volar locking } \\
\text { plate }\end{array}$} & \multirow{2}{*}{ P value } \\
\cline { 2 - 5 } & Mean & SD & Mean & SD & \\
\hline 3 weeks & 16.85 & 2.53 & 13.25 & 3.19 & $<0.001^{* *}$ \\
\hline 6 weeks & 12.15 & 2.99 & 9.35 & 2.20 & $0.002^{*}$ \\
\hline 3 months & 8.65 & 2.97 & 6.25 & 1.80 & 0.004 \\
\hline 6 months & 6.30 & 3.11 & 4.10 & 2.59 & $0.02^{*}$ \\
\hline
\end{tabular}

* Significant, ***Highly significant

Table 7: Gartland and werley score

\begin{tabular}{|c|c|}
\hline Excellent & $0-2$ \\
\hline Good & $3-8$ \\
\hline Fair & $9-20$ \\
\hline Poor & $\geq 21$ \\
\hline
\end{tabular}

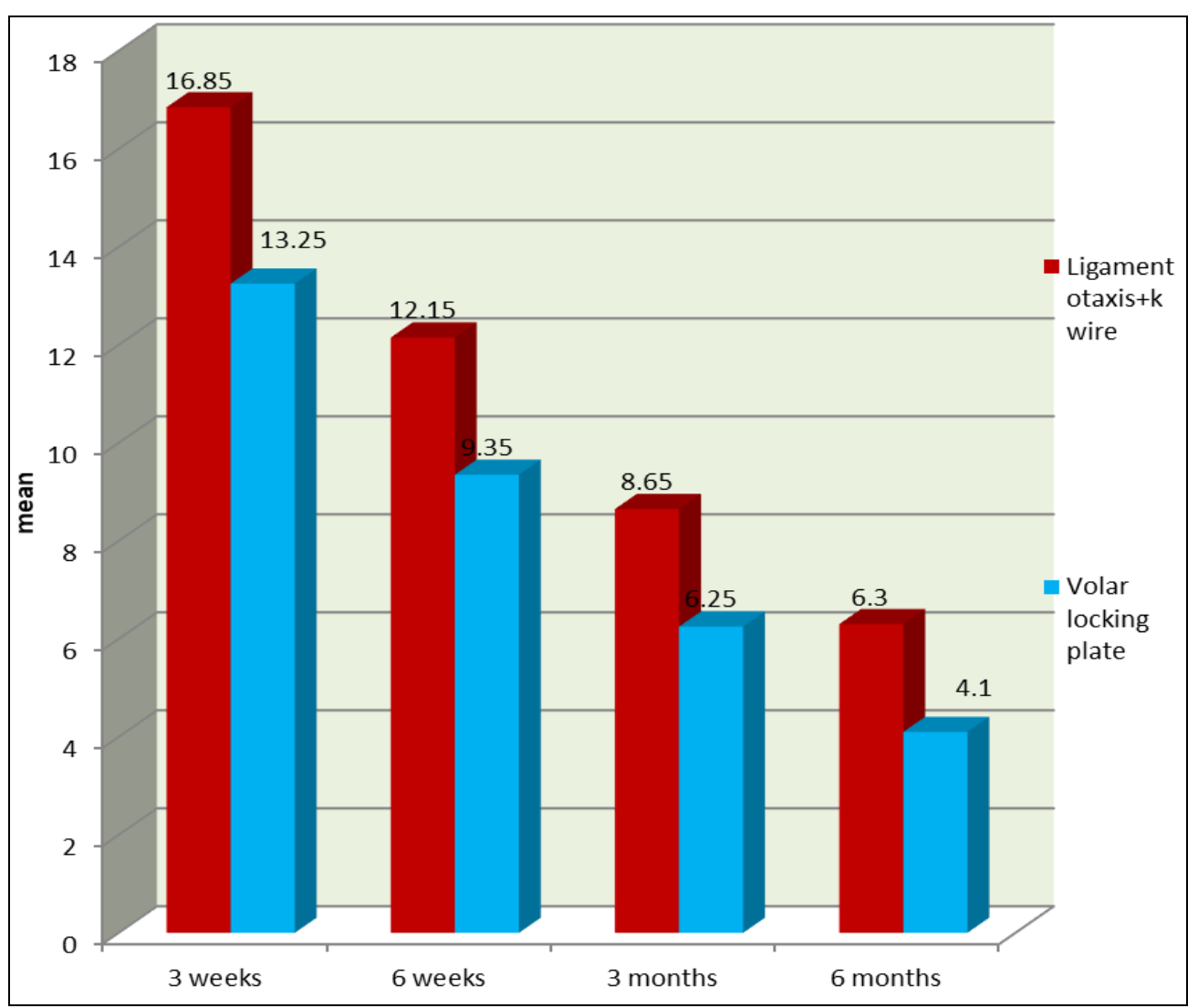

Fig 5: Comparison between Gartland \& Werley score in both the treatment groups at Varius intervals

Table 8: Radiological outcome using Sarmiento Radiological Score

\begin{tabular}{|c|c|c|c|c|c|c|}
\hline Treatment & Excellent & Good & Fair & Poor & Chi square value & P value \\
\hline Ligamentotaxis + k wire & $2(10)$ & $9(45.0)$ & $4(20.0)$ & $5(25)$ & \multirow{2}{*}{9.60} & \multirow{2}{*}{$0.02^{*}$} \\
\hline Volar locking plate & $8(40)$ & $6(30.0)$ & $6(30.0)$ & 0 & & \\
\hline
\end{tabular}

Chi square test; $* p<0.05$ statistically significant

Radiological outcome of Ligamentotaxis and volar locking plate were compared with Sarmiento radiological score into Excellent, Good, Fair and Poor. Ligamentotaxis having Mean 2(10.0), 9(45.0), 4(20.0) and 5(25.0) respectively, whereas, Volar locking plate had mean 8(40.0), 6(30.0), 6(30.0) and 0 respectively.

It was found to be statically significant by $P$ value 0.02 . In our study in terms of post-operative radiological outcome by Sarmiento Radiological Score; Volar locking plate was superior to Ligamentotaxis in distal end radius fractures 


\section{Statistical methods}

All statistical procedures were performed using Statistical Package for Social Sciences (SPSS) $20.0^{[15]}$. Calculations for power $(80 \%)$ of study will be performed before commencement of the study. All quantitative variables expressed in mean and SD. Qualitative variables will be expressed in percentages. Shapiro-Wilk test was used for testing the normality assumption of the data. Chi square and student $\mathrm{t}$ test was used for association between variables. Probablility value $(\mathrm{p}<0.05)$ was considered statistically significant.

\section{Discussion}

In our study, the average age of patients with Distal end Radius fracture was 47.7 years.

We noticed that the population more than 50 years of age, had increased incidence of distal end Radius fractures. Female population showed an increased incidence of distal end radius fractures. Distal end radius fractures in $50.0 \%$ patients were due to road accident, $(n=20)$ and self-fall accounted to $50.0 \%$ of cases in our study $(n=20)$.

On analysis of occupation based injuries of the distal radius, it was noticed that there was more incidence in House wives and Manual laborers. Study on the intra and post operative complications it was found that, there was more chance of iatrogenic fracture and breakage of implant in Ligamentotaxis. But neurovascular injury was seen more in invasive procedure, ie., Volar locking plate. Since Volar locking plate fixation is based on open reduction and internal fixation technique, it will attain more anatomic reduction, stable rigid fixation \& there is decreased chance of malunion, joint stiffness as per our study.

Since Volar locking plate is done, based on open reduction and internal fixation principles of $\mathrm{AO}$, it will attain more anatomic reduction, and stable rigid fixation. We found that, the chances of malunion, and joint stiffness are far less than the other groups. But the incidence of Complex Regional Pain Syndrome was found to be equal in both techniques.

On the study of the postoperative functional outcome, Ligamentotaxis and volar locking plate were compared with Gartland and Werley score at 3 weeks, 6 weeks, 3 months, 6 months.

There was a statistically significant difference found between mean Gartland and Werley score on 3 weeks, 6 weeks, 3 months and 6 months. Since the study is based on Gartland and Werley score for evaluation of functional outcome, these values are of great significance.

In terms of post-operative functional outcome by using Gartland and Werley score, Volar locking plate is found to be superior to Ligamentotaxis in Comminuted Intra articular Fractures of Lower end of radius. When the post operative radiological outcome was studies by Sarmiento Radiological Score; Volar locking plate is found to be superior compared with Ligamentotaxis in the treatment of Comminuted Intra articular Fractures of Lower end of radius.

\section{Case study Ligamentotaxis $+k$ wire}

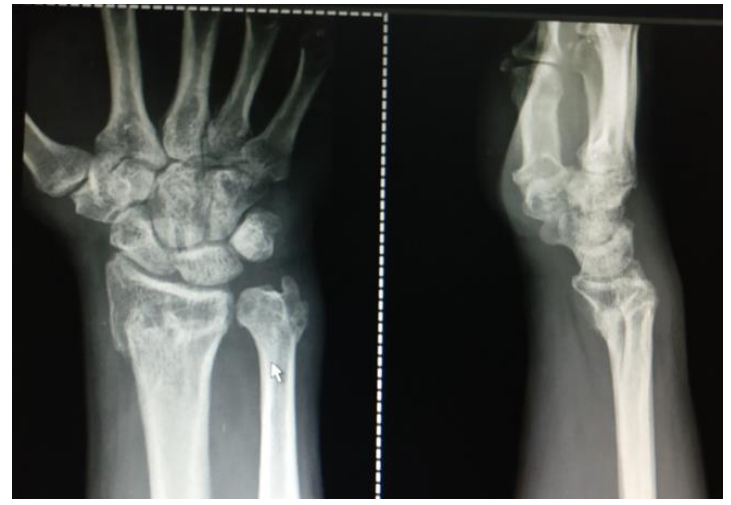

Pre-op

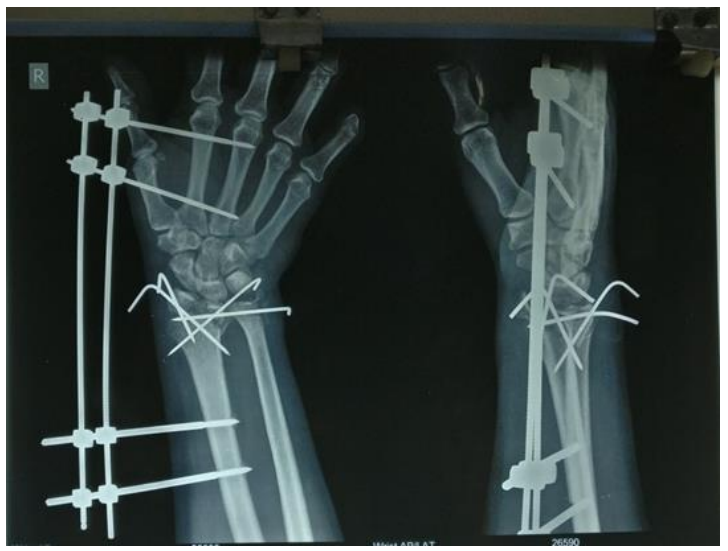

Post-op

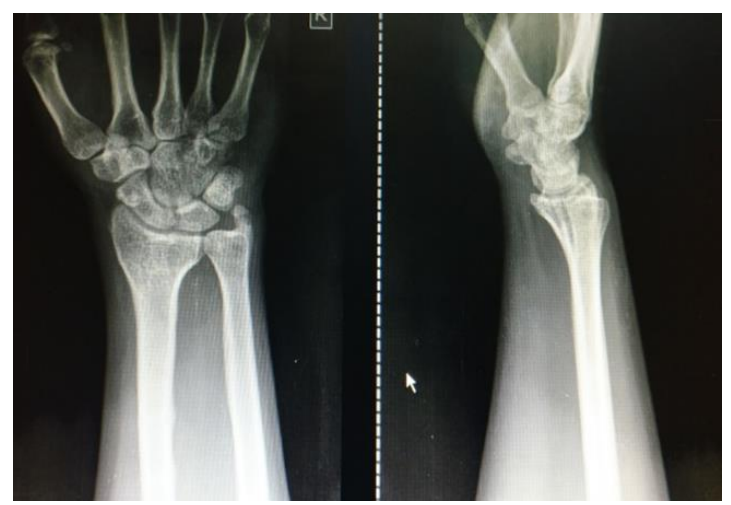

After implant removal

Case study ORIF with volar locking plate

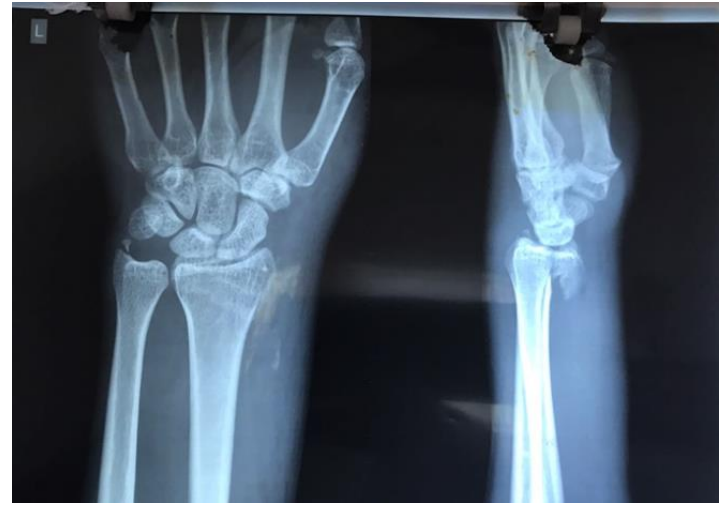

Pre-op 


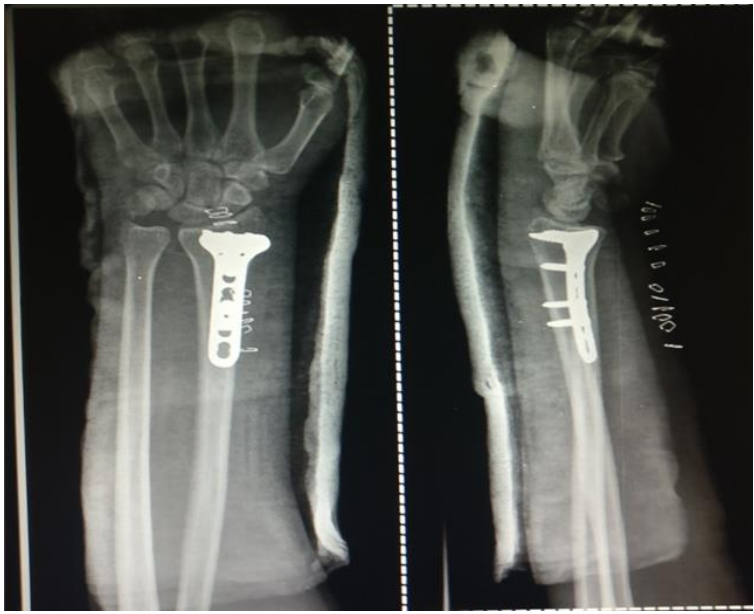

Post-op

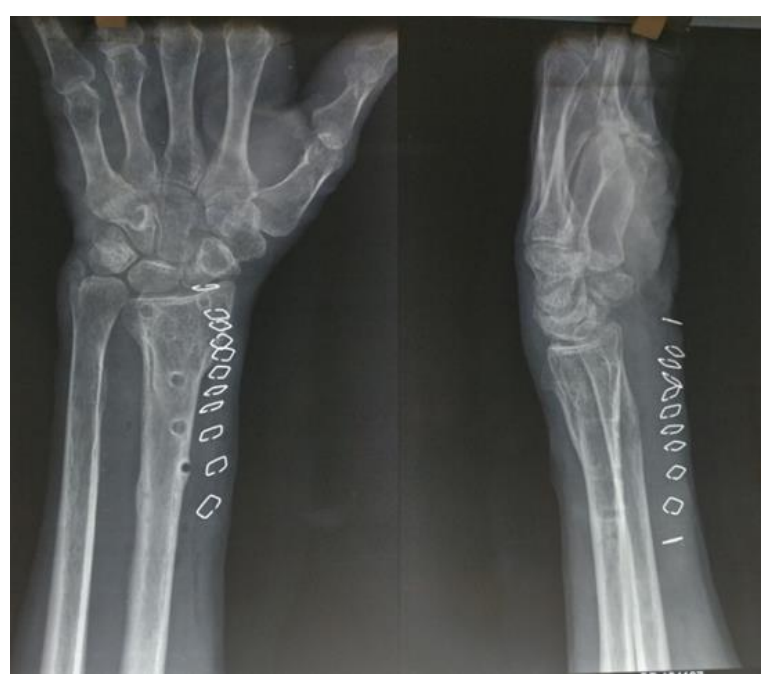

After implant removal

\section{Conclusions}

In case of distal end radius fracture treatment, osteosynthesis with direct open reduction and internal fixation using a volar locking plate has particular favorable advantages over Ligamentotaxis with $\mathrm{K}$ wires in terms of anatomical reduction under direct vision and rigid fixation.

In our study we found there are significant benefits for volar locking plate over Ligamentotaxis followed up at specified intervals post-operatively and compared using Gartland and Werley Score. This was achieved by early mobilization of the wrist joint, who had undergone volar locking plate.

We also found that radiological outcome of volar locking plate at 6 months is better compared to Ligamentotaxis in terms of Sarmiento Radiological Score.

Considering the decreased intra operative, as well as postoperative complications, superior functional and radiological outcomes, we conclude that Volar locking plate is better than Ligamentotaxis in the management of Comminuted intra articular fractures of the Lower end of radius.

Funding: No funding sources

Conflict of interest: None declared

Ethical approval: The study was approved by the institutional ethics committee of our Institution.
Jenkins DK, Sweo TD et al. Effects of distal radius malunion on wrist joint mechanics. J Hand Surg Am. 1990; 15:721-7.

2. Koval KJ, Zuckerman JD, Kenneth E. 2nd ed. Philadelphia, USA: Lippincott williams and Wilkins; Handbook of Fractures.

3. Meena S, Sharma P, Sambharia AK, Dawar A. Fractures of Distal Radius: An Overview. J Family Med Prim Care. 2014; 3(4):325-32.

4. Agee JM. External fixation -Technical advances based upon multiplaner ligamentotaxis. Orthop Clin North Am. 1993; 24:265.

5. Connolly JF. Non-operative fracture treatment. In Rockwood \& Green's Fractures in Adults. Bucholz RW, Heckman JD Eds. Fifth edition, Philadelphia: Lippincott Williams \& Wilkins. 2001; 1:142.

6. Berglund LM, Messer TM. Complications of volar plate fixation for managing distal radius fractures. J Am Acad Orthop Surg. 2009; 17(6):369-77. [PubMed]

7. Bowers WH. The distal radioulnar joint, in Green's Operative Hand Surgery, Chapter 30, 4th Edn, eds Green D. P., Hotchkiss R. N., Pederson W. C., editors. (Philadelphia, Pennsylvania: Churchill Livingstone;), 1999, 986-1032.

8. Berger RA. The ligaments of the wrist. A current overview of anatomy with considerations of their potential Huang J, Hanel D. Anatomy and biomechanics of the distal radioulnar joint. Hand Clin. 2012; 28:157163. doi: 10.1016/j.hcl.2012.03.002. PMid: 22554659

9. Kwon BC, Seo BK, Im HJ, Baek GH. Clinical and radiographic factors associated with distal radioulnar joint instability in distal radius fractures. Clin Orthop Relat Res. 2012; 470(11):3171-3179. doi: 10.1007/s11999-012-2406-4. PMid: 22669548; PMCid: PMC3462878

10. Havemann D, Busse FW. Accident mechanisms and classifications in distal radius fractures. Langenbecks Arch ChirSuppl II Verh Dtsch Ges Chir. 1990, 639-42.

11. Chen NC, Jupiter JB. Management of distal radius fractures. J Bone Joint Surg Am. 2007; 89:2051-2062.

12. Gartland JJ Jr, Werley CW. Evaluation of healed Colles' fracture. J Bone Joint Surg Am. 1951; 33:895-907 [PubMed]

13. Sarmiento A, Pratt G, Berry N, Sinclair W. Colles' fractures. Functional bracing in supination. J Bone Joint Surg Am. 1975; 57(3):311-317. [PubMed]

14. https://www.ncbi.nlm.nih.gov/pubmed/?term=Anthony\% 20D\%5BAuthor\%5D\&cauthor=true\&cauthor_uid $=15065$ 481

\section{References}

1. Pogue DJ, Vegas SF, Patterson RM, Peterson PD, 